\title{
Article \\ Nickel-Doped ZnO Nanowalls with Enhanced Electron Transport Ability for Electrochemical Water Splitting
}

\author{
Bing-Chang Jiang and Sheng-Hsiung Yang * (D) \\ Institute of Lighting and Energy Photonics, College of Photonics, National Yang Ming Chiao Tung University, \\ Tainan 71150, Taiwan; ben0658228@gmail.com \\ * Correspondence: yangsh@mail.nctu.edu.tw
}

Citation: Jiang, B.-C.; Yang, S.-H. Nickel-Doped ZnO Nanowalls with Enhanced Electron Transport Ability for Electrochemical Water Splitting. Nanomaterials 2021, 11, 1980. https:/ / doi.org/10.3390/nano11081980

Academic Editor: Alberto Villa

Received: 9 July 2021

Accepted: 29 July 2021

Published: 31 July 2021

Publisher's Note: MDPI stays neutral with regard to jurisdictional claims in published maps and institutional affiliations.

Copyright: (C) 2021 by the authors Licensee MDPI, Basel, Switzerland. This article is an open access article distributed under the terms and conditions of the Creative Commons Attribution (CC BY) license (https:/ / creativecommons.org/licenses/by/ $4.0 /)$.

\begin{abstract}
This article reports on the growth of $3 \mathrm{~mol} \%$ nickel (Ni)-doped zinc oxide nanowalls (ZnO NWLs) using the hydrothermal method. Morphological investigation as well as electrical conductivity of the undoped and Ni-doped ZnO NWLs was also discussed. The surface roughness of the formed ZnO NWLs was reduced after Ni-doping. The pore size of Ni-doped ZnO NWLs can be controlled by changing the concentration of hexamethylenetetramine (HMT). As the HMT concentration increased, the pores became larger with increasing surface roughness. The electrical conductivity of the electron-only device based on the Ni-doped ZnO NWLs was higher than that of the undoped one, and it was decreased with increasing the HMT concentration. Our results reveal that Ni-doping and adjustment of the HMT concentration are two key approaches to tune the morphology and electrical properties of ZnO NWLs. Finally, the undoped and Ni-doped ZnO NWLs were used as the catalyst for electrochemical water splitting. The Ni-doped ZnO NWLs with the HMT concentration of $1 \mathrm{mM}$ showed the highest electrochemical performance, which can be attributed to the increased surface area and electrical conductivity.
\end{abstract}

Keywords: nickel-doped; zinc oxide nanowalls; surface roughness; pore size; electrochemical water splitting

\section{Introduction}

The continuous development in the growth of nanostructured metal oxides is a key issue for optoelectronic applications in sensors [1], transistors [2], and others [3,4]. A deeper understanding of growth mechanism of metal oxide nanostructures with high quality and low cost is extremely important for future production. At present, common metal oxides include titanium oxide $\left(\mathrm{TiO}_{2}\right)$, zinc oxide $(\mathrm{ZnO})$, and tungsten oxide $\left(\mathrm{WO}_{x}\right)$. The electron mobility of $\mathrm{TiO}_{2}$ and $\mathrm{WO}_{x}$ is reported to be $0.1-4$ and $12 \mathrm{~cm}^{2} / \mathrm{Vs}[5,6]$, respectively, while $\mathrm{ZnO}$ possesses 10-fold higher electron mobility (110-138 $\mathrm{cm}^{2} / \mathrm{Vs}$ ) with lower calcination temperatures [5,7]. It is reported that $\mathrm{ZnO}$ can be obtained from its precursor film by annealing at $150-200{ }^{\circ} \mathrm{C}$ [5]; however, this requires relatively higher calcination temperatures of up to $500{ }^{\circ} \mathrm{C}$ to obtain high-quality $\mathrm{WO}_{x}$ [6]. Specific nanostructures of the above three materials can be grown via the hydrothermal method, and the growth temperature of $\mathrm{ZnO}$ is the lowest among the three oxides. For example, $\mathrm{TiO}_{2}$ or $\mathrm{WO}_{x}$ nanorods can be grown on the substrate from their precursor solutions at $170{ }^{\circ} \mathrm{C}$ with the aid of Teflon-lined autoclaves [8,9], while $\mathrm{ZnO}$ nanorods are easier to grow on the substrate at a lower temperature of $95^{\circ} \mathrm{C}$ [10]. Besides, $\mathrm{ZnO}$ possesses many fascinating properties, including earth abundance, non-toxicity, high transmittance in the visible range, and large piezoelectric response [11-13]. Highly ordered ZnO nanostructures such as nanorods [14], nanowires [15-17], nanoflowers [18], and nanowalls (NWLs) [19] have been prepared by chemical vapor deposition, metal organic chemical vapor deposition, the molecular beam epitaxy method, and microwave synthesis [20]. Those processes require expensive equipment, high reaction temperatures, and complicated parameter settings that usually 
lead to high production costs. In order to prevent those drawbacks, the low-cost hydrothermal method has been gradually adapted, which permits facile fabrication and the use of flexible substrates. To date, numerous studies concerning $\mathrm{ZnO}$ nanostructures using the hydrothermal method have been published in the literature in relation to nanorods [21-23], nanowires [24-26], nanoflowers [27], and NWLs [28-30]. ZnO nanowires and nanoflowers are usually inhomogeneously distributed on the substrate with random layer thickness, with difficulties in device fabrication. ZnO nanorods and NWLs provide two-dimensional structures and both can be grown vertically on the substrate. NWLs have a much thinner wall thickness and a larger surface area [30], which is beneficial for carrier extraction and transport to reach high device efficiency. As a result, this study is focused on preparation as well as the morphological and electrical investigation of ZnO NWLs.

ZnO NWLs are reported to have intertwined honeycomb or sponge-like nanostructures $[5,30]$. There are two ways to grow NWLs on the substrate via the hydrothermal method as per the previous reports [28,29]. The first way contains three steps, including the deposition of $\mathrm{ZnO}$ seed layer, growth of $\mathrm{ZnO}$ nanorods, and etching of nanorods with an aqueous $\mathrm{KOH}$ solution to form NWLs. The formation of NWLs is ascribed to defectselective dissolution in (001) planes and etching along the c-axis by $\mathrm{OH}^{-}$in chemical bath. Shin et al. firstly prepared $\mathrm{ZnO}$ NWLs by etching in $\mathrm{KOH}$ solution [31]. A $\mathrm{ZnO}$ sidewall of approximately $30 \mathrm{~nm}$ was formed by the partial dissolution of the (001) surface of the $\mathrm{ZnO}$ thin film after etching for $15 \mathrm{~min}$. The formed $\mathrm{ZnO}$ NWLs were utilized as the electron transport layer (ETL) for fabricating inverted polymer solar cells, revealing a power conversion efficiency (PCE) value of $1.8 \%$. Liang et al. also prepared $\mathrm{ZnO}$ NWLs using the similar etching technique to form much denser structures [28]. The inverted polymer solar cells based on dense ZnO NWLs reached a PCE value of $2.14 \%$. The second way also involves three steps, including the deposition of $\mathrm{ZnO}$ compact layer, thermal evaporation of an aluminum (Al) thin layer, and growth of $\mathrm{ZnO}$ NWLs in chemical bath. The formation mechanism of NWLs is attributed to prohibition of $\mathrm{ZnO}$ growth along the [001] direction while allowing the occurrence of lateral growth, as proposed by $\mathrm{Chu}$ and coworkers [27]. The $\mathrm{ZnO}$ NWLs were grown on silicon wafer using an aluminum mask in conjunction with a hydrothermal method, which produce two cathodoluminescence peaks at 378 and $560 \mathrm{~nm}$. They also found that $\mathrm{ZnO}$ nanoflowers would form on NWLs by controlling the concentration of hexamethylenetetramine (HMT) and reaction time. Tang et al. also used the same method to grow ZnO NWLs with a large number of sponge-like pores [5]. The thickness of the film and sidewalls was measured to be 320 and $30-80 \mathrm{~nm}$, respectively. The formed ZnO NWLs were utilized as the ETL for the fabrication of perovskite solar cells with the configuration of indium tin oxide (ITO)/ZnO NWLs/perovskite/Spiro-OMeTAD/Ag. The optimized device achieved a moderate PCE value of $13.6 \%$. Feng et al. changed the molar ratio of the two starting materials zinc nitrate hexahydrate and HMT to prepare $\mathrm{ZnO}$ NWLs [10]. When the molar ratio of zinc nitrate hexahydrate and HMT was controlled to $1: 1$ or 2:1, similar NWL structures were formed. As the concentration of HMT was increased (molar ratio = 1:2), flower-like ZnO nanoparticles on top of NWLs were observed. It is seen that HMT is a popular chemical compound used in the literature to control or modify the structure of $\mathrm{ZnO}$ nanomaterials [20]. To date, changing the concentration of HMT has led to complex $\mathrm{ZnO}$ nanostructures. The preparation of ZnO NWLs with uniform thickness and controllable pore size is still undergoing.

In the field of water splitting, several state-of-the-art works have been reported. Reddy et al. utilized $1 \mathrm{~mol} \%$ Ni-doped $\mathrm{ZnO}$ structures as the catalyst that showed the maximum photoelectrochemical activity under visible light illumination [32]. The maximum current density of $\sim 3.28 \mathrm{~mA} / \mathrm{cm}^{2}$ at a $0.1 \mathrm{M} \mathrm{NaOH}$ electrolyte demonstrated a superior charge separation. Khan et al. fabricated Ni-doped $\mathrm{ZnO}$ thin films for efficient overall water splitting [33]. The incorporation of $\mathrm{Ni}^{2+}$ significantly enhanced the photoelectrochemical performance by improving the charge transport properties and conductivity of the $\mathrm{ZnO}$ host matrix. In this work, we first demonstrate the preparation of nickel (Ni) doped $\mathrm{ZnO}$ NWLs via the hydrothermal method. The increment in electrical conductivity of Ni-doped 
ZnO NWLs was verified from electrical measurement of electron-only devices. In order to control the pore size of $\mathrm{ZnO} N W L s$, the molar concentration of HMT was controlled from 1 to $5 \mathrm{mM}$, while the molar concentration of zinc nitrate hexahydrate was fixed to $0.025 \mathrm{M}$ in our system. The effects of HTM concentration on morphology and surface roughness of ZnO NWLs were examined by scanning electron microscopy (SEM) and atomic force microscopy (AFM). We found that the pore size of NWLs could be fine-tuned by the introduced HMT amount. Moreover, the flower-like aggregates on ZnO NWLs were completely suppressed by controlling the HMT concentration at lower than $7 \mathrm{mM}$. Apart from SEM observations, we provided a series of AFM topographic images as well as surface roughness data to support our results, which have rarely been reported in the literature. The elemental analysis of the undoped and Ni-doped ZnO NWLs was verified by the energy-dispersive spectroscopy (EDS) technique. The transmission and absorption properties of different types of ZnO NWLs were also investigated. Finally, ZnO NWLs were used as the catalyst for water splitting application. A linear sweep voltammetry (LSV) experiment was applied to study electrochemical activity of the prepared ZnO NWLs.

\section{Materials and Methods}

\subsection{Materials}

ITO glass substrates $(7 \Omega / \square)$ were purchased from Merck (Darmstadt, Germany). The original size of ITO substrates was $37 \times 40 \mathrm{~cm}^{2}$, and they were cut into small pieces of $2 \times 2 \mathrm{~cm}^{2}$ for further use. Zinc acetate dihydrate $\left(\mathrm{C}_{4} \mathrm{H}_{10} \mathrm{O}_{6} \mathrm{Zn}\right.$, purity $\left.98.0-101.0 \%\right)$, zinc nitrate hexahydrate $\left(\mathrm{H}_{12} \mathrm{~N}_{2} \mathrm{O}_{12} \mathrm{Zn}\right.$, purity $\left.99 \%\right)$, and nickel nitrate hexahydrate $\left(\mathrm{H}_{12} \mathrm{~N}_{2} \mathrm{NiO}_{12}\right.$, purity 98\%) were all purchased from Alfa Aesar (Ward Hill, MA, USA). HMT $\left(\mathrm{C}_{6} \mathrm{H}_{12} \mathrm{~N}_{4}\right.$, purity $99 \%$ ) was purchased from SHOWA (Osaka, Japan). Monoethanolamine $\left(\mathrm{C}_{2} \mathrm{H}_{7} \mathrm{NO}\right.$, purity $99 \%)$ and 2-methoxyethanol $\left(\mathrm{C}_{3} \mathrm{H}_{8} \mathrm{O}_{2}\right.$, purity $\left.99+\%\right)$ were bought from Acros (Geel, Belgium). Other reagents and solvents were bought from Alfa Aesar (Ward Hill, MA, USA) and used without further purification.

\subsection{Preparation of $\mathrm{ZnO} N W L s$}

Prior to the growth of ZnO NWLs, the ITO substrates were cleaned sequentially with deionized (DI) water, acetone and isopropanol for 20 min each in ultrasonic bath, followed by UV-ozone exposure for $30 \mathrm{~min}$. The ultrasonic cleaner (model D150, 150 W) was manufactured by DELTA Ultrasonic Co., Ltd. (New Taipei City, Taiwan). ZnO NWLs were grown using a 3-step deposition method. First, the $\mathrm{ZnO}$ compact layers were formed by spin-coating from a precursor solution at $3000 \mathrm{rpm}$ for $30 \mathrm{~s}$ on the ITO substrates. The precursor solution was prepared by mixing zinc acetate dihydrate $(0.2195 \mathrm{~g}, 0.1 \mathrm{~mol})$ and monoethanolamine $(0.061 \mathrm{~g}, 0.1 \mathrm{~mol})$ in $10 \mathrm{~mL}$ of 2-methoxyethanol and heating at $60^{\circ} \mathrm{C}$ for $2 \mathrm{~h}$ with stirring. After spin-coating, the precursor films were immediately calcinated at $300{ }^{\circ} \mathrm{C}$ for $30 \mathrm{~min}$ in air. The high-temperature oven (model OV-455) was manufactrured by PANCHUN Scientific Corp. from Taiwan. Second, a $30 \mathrm{~nm}$-thick aluminum layer was deposited on the $\mathrm{ZnO}$ compact layer by thermal evaporation. Third, the NWLs were grown in a growth solution at $80^{\circ} \mathrm{C}$ for $50 \mathrm{~min}$. Two separate solutions were prepared in advance. One was zinc nitrate hexahydrate $(0.144 \mathrm{~g}, 0.48 \mathrm{mmol})$ dissolved in $20 \mathrm{~mL}$ of DI water, and the other was HMT dissolved in $20 \mathrm{~mL}$ of DI water. The concentration and weight of HMT were controlled to be $1 \mathrm{mM}(0.0028 \mathrm{~g}), 3 \mathrm{mM}(0.0084 \mathrm{~g})$ and $5 \mathrm{mM}(0.014 \mathrm{~g})$ to study the effect of HMT concentration on the morphology of ZnO NWLs. The zinc nitrate hexahydrate solution was then poured into the HMT solution to form the growth solution. For Ni doping, nickel nitrate hexahydrate $(0.0043 \mathrm{~g}, 0.0147 \mathrm{mmol})$ was added in the zinc nitrate hexahydrate solution. The Ni-doping content was $3 \mathrm{~mol} \%$ relative to zinc nitrate hexahydrate. After growth, the substrates were taken out, rinsed with DI water, and purged with nitrogen flow, followed by calcination at $300{ }^{\circ} \mathrm{C}$ for $30 \mathrm{~min}$ in air to form final $\mathrm{ZnO}$ NWLs. The schematic illustration of the $\mathrm{ZnO}$ NWLs formation is depicted in Figure 1. 


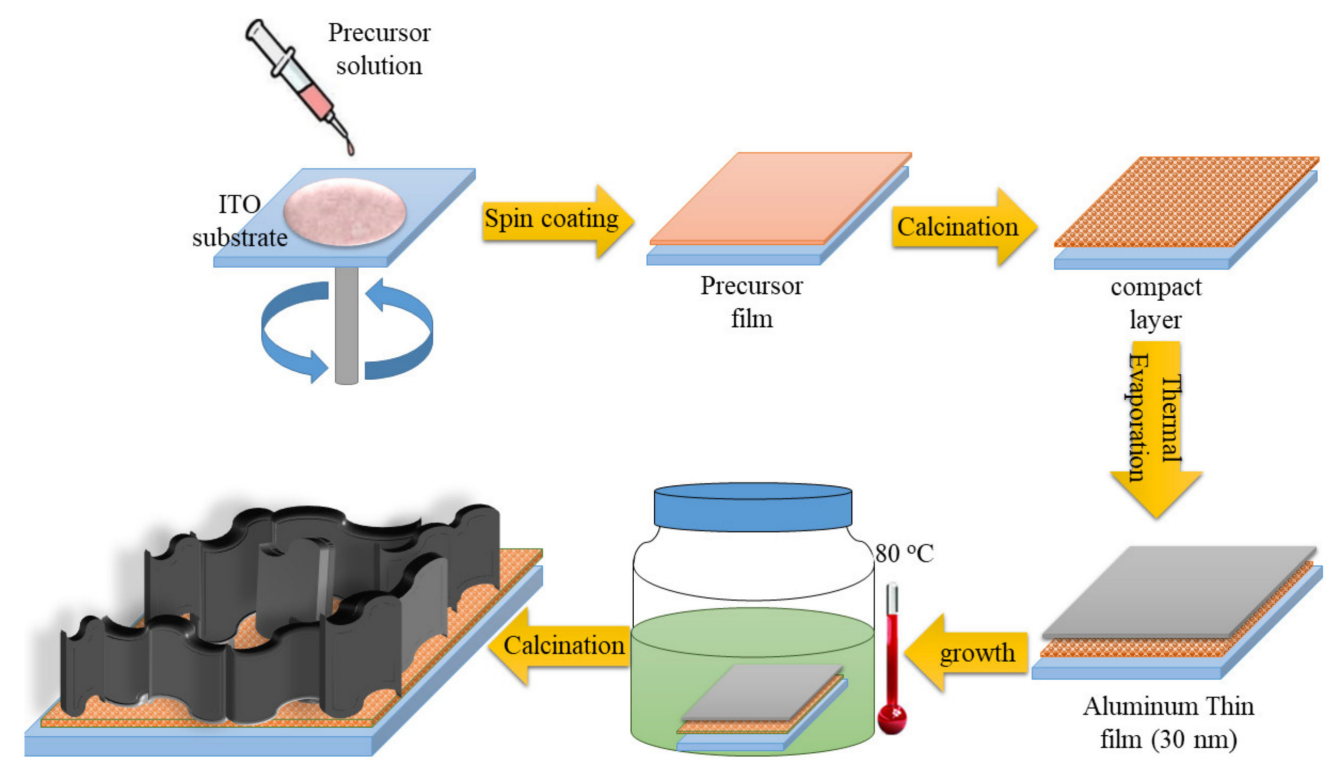

Figure 1. Schematic illustration of the formation of ZnO NWLs.

\subsection{Characterization Methods}

The top-view and cross-sectional SEM micrographs of samples were investigated with an ultra-high resolution ZEISS Auriga SEM. The EDS analyzer (Quantax, BRUKER, Billerica, MA, USA) was also equipped on the same SEM for elemental analysis. The surface morphology and roughness of ZnO NWLs were performed using a Bruker Innova AFM (Billerica, MA, USA). The transmission and absorption spectra of samples were recorded with a Princeton Instruments Acton 2150 spectrophotometer equipped with a Xe lamp as the light source. The current-voltage (I-V) characteristics of electron-only devices were measured using an Agilent 4155C semiconductor parameter analyzer. The LSV experiment was performed on an AUTOLAB PGSTAT30 potentiostat for electrochemical water splitting test. The electrochemical cell was composed of 3 electrodes, with $\mathrm{Ag} / \mathrm{AgCl}$ (Metrohm AG) as the reference electrode, $\mathrm{Pt}$ wire as the counter electrode, and ZnO NWLs samples as the work electrode. The electrolyte was $0.1 \mathrm{M} \mathrm{KOH}$ aqueous solution. The scan rate and active area of each sample were $5 \mathrm{mV} / \mathrm{s}$ and $1 \mathrm{~cm}^{2}$, respectively.

\section{Results and Discussion}

\subsection{Morphological Investigation}

The top-view and cross-sectional SEM micrographs of the undoped and Ni-doped ZnO NWLs with the HMT concentration of $1 \mathrm{mM}$ are shown in Figure 2. The morphology of our undoped ZnO NWLs looks similar with other reports in the literature [11,14,29]. Compared with the undoped $\mathrm{ZnO}$, Ni-doped $\mathrm{ZnO}$ NWLs have more staggered networks, indicative of greater surface area. Both the undoped and Ni-doped ZnO NWLs showed sponge-like nanostructures through SEM observation. Moreover, the pores of Ni-doped ZnO NWLs are obviously smaller and uniform than the undoped one, as shown in the insets in Figure 2a,b. The thickness of the undoped and Ni-doped ZnO NWLs is estimated to be 250 and $150 \mathrm{~nm}$, respectively, from the cross-sectional SEM images in Figure 2c,d. Apart from morphology, surface roughness is also an important issue for the construction of optoelectronic devices with high performance. In this part, AFM technique was utilized to investigate topographic images and average roughness $\left(\mathrm{R}_{\mathrm{a}}\right)$ of the prepared $\mathrm{ZnO}$ NWLs. The corresponding AFM images and $R_{a}$ values are revealed in Figure 3. It is clearly seen that both the undoped and Ni-doped ZnO NWLs have inter-connected wall structures and the latter possesses denser morphologies, which is in good accordance with SEM observations. The $R_{a}$ values of the undoped and Ni-doped ZnO NWLs were estimated to be 18 and $12.2 \mathrm{~nm}$, respectively, revealing that $\mathrm{Ni}$-doping would decrease surface roughness 
of ZnO NWLs. From literature survey, we learn that AFM topographic images of $\mathrm{ZnO}$ NWLs are less reported, while corresponding $R_{a}$ value has not been disclosed so far. It is well known that lower roughness has a positive impact for reducing leakage current and enhancing device performance. This is the first time that complete AFM images and roughness measurements of $\mathrm{ZnO}$ NWLs have been demonstrated.

To study the effects of the HMT concentration on the morphology of ZnO NWLs, the HMT molar concentration was varied from 1 to $5 \mathrm{mM}$, while the concentration of zinc nitrate hexahydrate was fixed at $25 \mathrm{mM}$. The top-view SEM images of the Ni-doped ZnO NWLs with 1, 3, and 5 mM HMT are depicted in Figures $2 b$ and $4 a, b$, respectively. All of these samples showed sponge-like nanostructures. It can be seen that the pores of ZnO NWLs significantly become larger as the HMT concentration increases. The crosssectional SEM images of the Ni-doped ZnO NWLs with different HMT concentrations are displayed in Figures $2 \mathrm{~d}$ and $4 \mathrm{c}, \mathrm{d}$, respectively. As shown in Figure $4 \mathrm{~d}$, the ZnO NWLs with $5 \mathrm{mM}$ HMT have the largest and intact nanosheets among three samples; smaller and denser nanosheets were formed when using 1 or 3 mM HMT. Based on these crosssectional SEM images, the thickness of the Ni-doped ZnO NWLs with 1, 3 and $5 \mathrm{mM}$ HMT is estimated to be 150, 175, and $250 \mathrm{~nm}$, respectively. It was observed that $\mathrm{ZnO}$ nanosheets grew larger and intact as the HMT concentration increased. The reason to this phenomenon can be explained as follows. The hydrolysis of HMT in water produces $\mathrm{OH}^{-}$ hydroxyl ions which react with $\mathrm{Zn}^{2+}$ ions to form zinc hydroxide ions $\mathrm{Zn}(\mathrm{OH})_{4}{ }^{2-}$ [27]. Higher HMT concentration leads to more $\mathrm{Zn}(\mathrm{OH})_{4}{ }^{2-}$ ions in the solution to develop fast nucleation of $\mathrm{ZnO}$ crystallites. As the HMT concentration was increased to $7 \mathrm{mM}$, some flower-like aggregates formed (see Figure S1 in the supplementary information). Mirabella and coworkers proposed the growth kinetics and photocatalytic activity of ZnO NWLs [30], stating that a more interlaced structure and a higher density of NWLs were produced when incorporating extra ammonium hydroxide. Our study provides a different way to modify the morphology of ZnO NWLs by adjusting the HMT concentration. To the best of our knowledge, this is the first report that discusses relationship between the morphology of ZnO NWLs and HMT concentration. The AFM topographic and 3D images of the Ni-doped ZnO NWLs with HMT concentrations of 1, 3, and $5 \mathrm{mM}$ are shown in Figures $3 b, d$ and $5 a-d)$, respectively. It was found that AFM images of those ZnO NWLs are basically consistent with SEM observations. The $\mathrm{R}_{\mathrm{a}}$ values of the Ni-doped ZnO NWLs with HMT concentrations of 1,3, and $5 \mathrm{mM}$ were $12.2,20.4$, and $38.8 \mathrm{~nm}$, respectively. The surface roughness of ZnO NWLs was enlarged with increasing the HMT concentration, since the increased HMT concentration promoted fast nucleation of $\mathrm{ZnO}$ crystallites for the growth of NWLs. The EDS analysis confirms the existence of $\mathrm{Zn}, \mathrm{O}$, and Ni elements of the prepared Ni-doped ZnO NWLs using $1 \mathrm{mM}$ HMT (see Figure S2 in the Supplementary Information), in addition to In and Sn from the ITO substrate and the Al deposited layer by thermal evaporation. The actual Ni doping content was $2.5 \mathrm{wt} \%$ in $\mathrm{ZnO}$ NWLs. The observation of Al signal in ZnO NWLs was also reported by Chu's group when adopting the three-step deposition method [27]. 

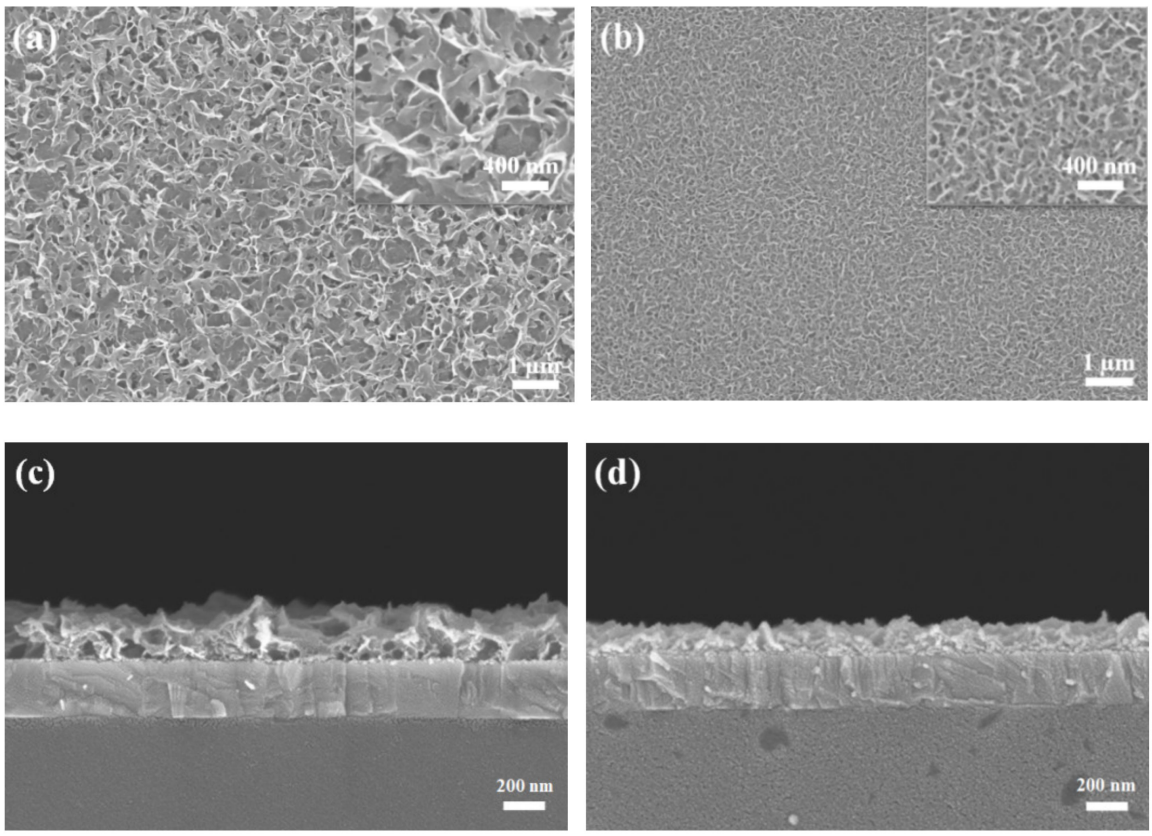

Figure 2. Top-view and cross-sectional SEM images of the $(\mathbf{a}, \mathbf{c})$ undoped and $(\mathbf{b}, \mathbf{d}) \mathrm{Ni}$-doped ZnO NWLs.
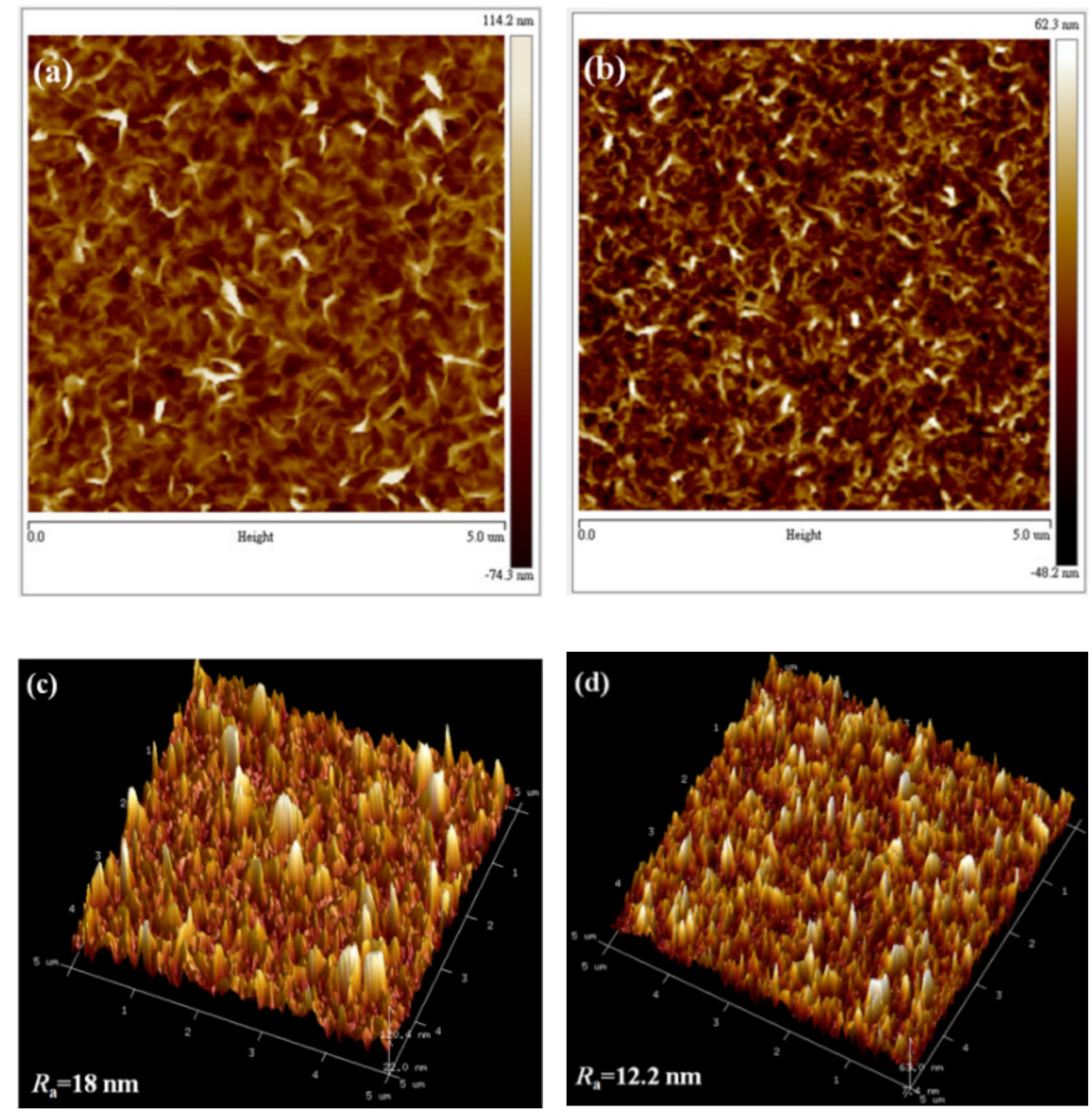

Figure 3. AFM topographic and 3D images of the $(\mathbf{a}, \mathbf{c})$ undoped and $(\mathbf{b}, \mathbf{d})$ Ni-doped ZnO NWLs. 

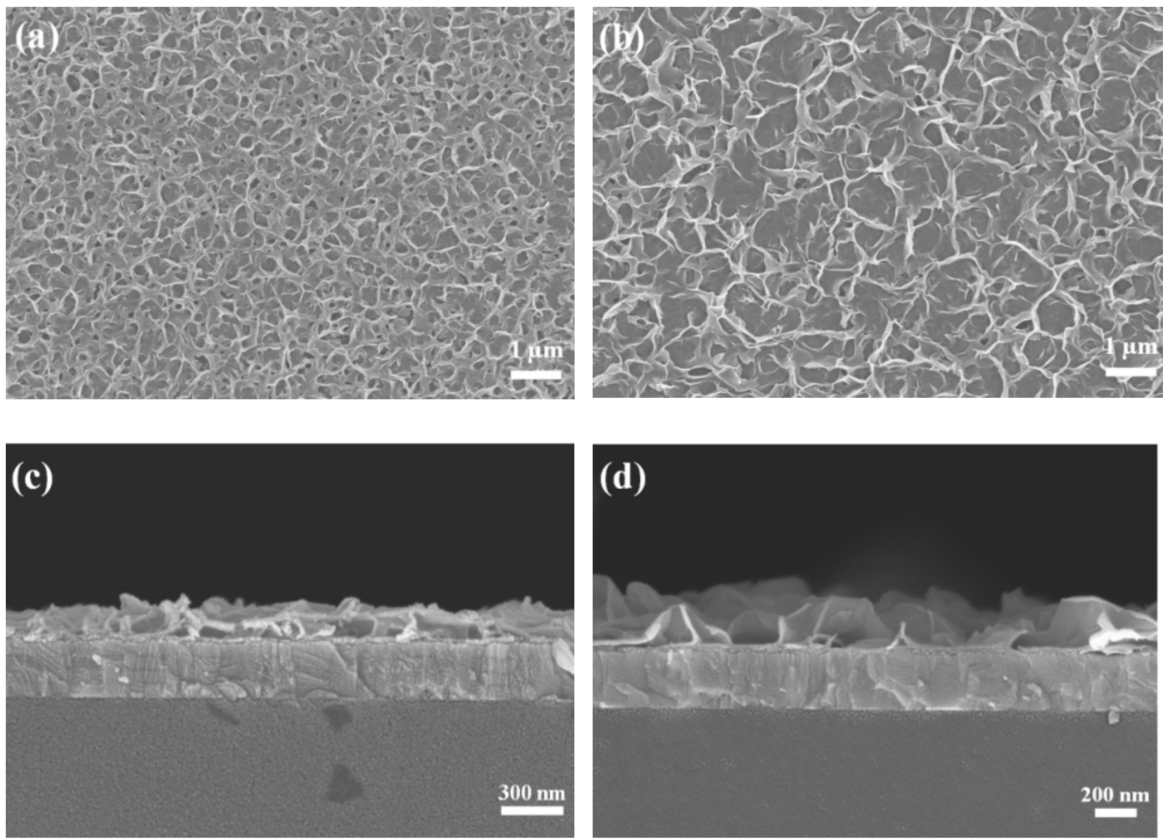

Figure 4. Top-view and cross-sectional SEM images of the Ni-doped ZnO NWLs with HMT concentrations of $(\mathbf{a}, \mathbf{c}) 3$ and $(\mathbf{b}, \mathbf{d}) 5 \mathrm{mM}$.
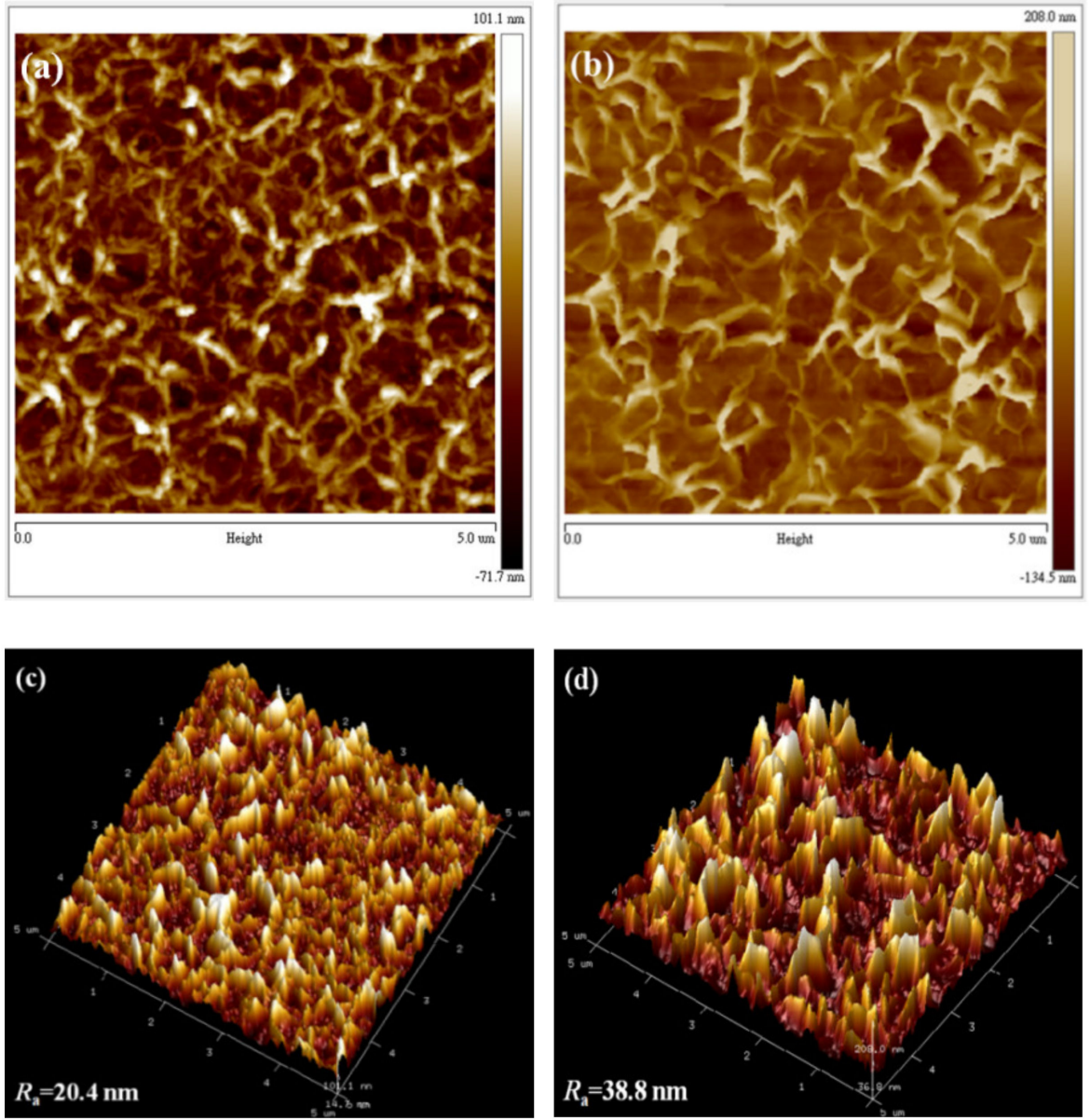

Figure 5. AFM topographic and 3D images of the Ni-doped ZnO NWLs with HMT concentrations of $(\mathbf{a}, \mathbf{c}) 3$ and $(\mathbf{b}, \mathbf{d}) 5 \mathrm{mM}$. 


\subsection{Optical Measurements}

The transmission and absorption spectra of the undoped and Ni-doped ZnO NWLs from 300 to $800 \mathrm{~nm}$ are shown in Figure 6a,b, respectively. The transmittance of ZnO NWLs reaches $80 \%$ at $400 \mathrm{~nm}$ and nearly $90 \%$ in the range of $500-800 \mathrm{~nm}$. The high transmittance of $\mathrm{ZnO}$ is beneficial for efficient photon input and/or output with reduced energy loss for different optoelectronic applications. The UV-Vis absorption spectra of different $\mathrm{ZnO}$ samples are depicted in Figure 6b. The absorption maximum of $\mathrm{ZnO}$ is located at $320 \mathrm{~nm}$, while a shoulder at around $360 \mathrm{~nm}$ for those Ni-doped ZnO NWLs is observed, which is in agreement with the previous literature [12]. Furthermore, the absorbance of $\mathrm{ZnO}$ becomes stronger with increasing the HMT concentration because of more $\mathrm{ZnO}$ nanosheets formed in the hydrothermal bath [27].
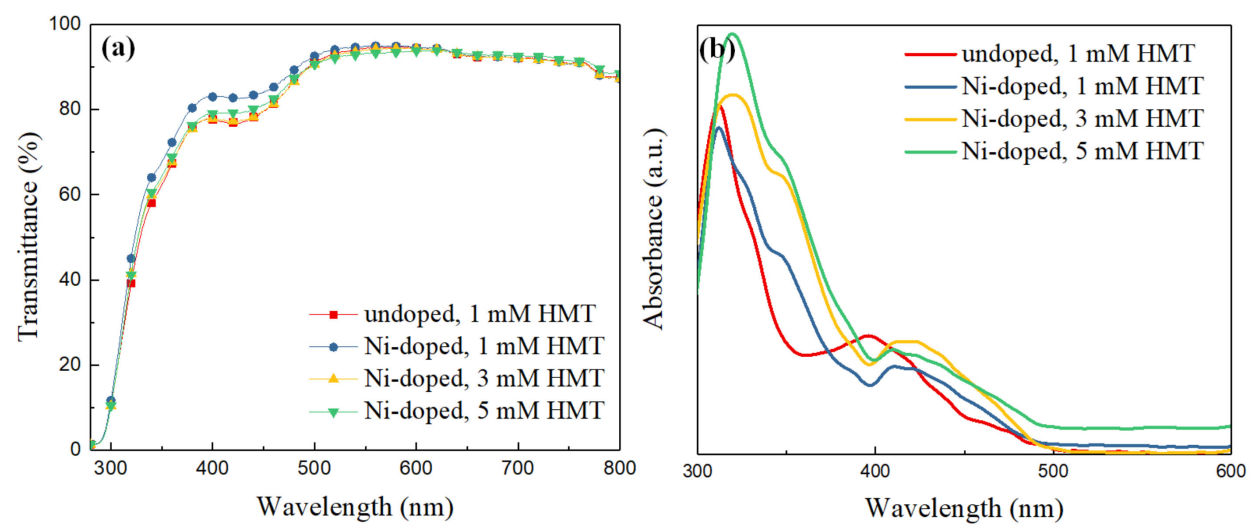

Figure 6. (a) Transmission and (b) absorption spectra of the undoped and Ni-doped ZnO NWLs with HMT concentrations of 1,3 , and $5 \mathrm{mM}$.

\subsection{Electrical Measurements}

To investigate the effect of Ni-doping and HMT concentration on the electrical conductivity of ZnO NWLs, electron-only devices with the structure of ITO/undoped or Ni-doped $\mathrm{ZnO}$ NWLs/Au were fabricated, and the corresponding I-V characteristics are shown in Figure 7. It is clearly seen that the devices based on the Ni-doped ZnO NWLs possess greater slope and higher electrical conductivity than that of the undoped one, indicative of enhanced electron transport ability for the Ni-doped ZnO NWLs. Moreover, the electrical conductivity of the Ni-doped ZnO NWLs with the HMT concentration of $1 \mathrm{mM}$ was higher than with 3 or $5 \mathrm{mM}$ HMT. This is because higher HMT concentration facilitates faster nucleation of $\mathrm{ZnO}$ that leads to an increment in the total thickness. With regard to the future application of the synthesized $\mathrm{ZnO}$ nanomaterials, both the amounts of Ni dopant and HMT should be carefully controlled to achieve high device performance.

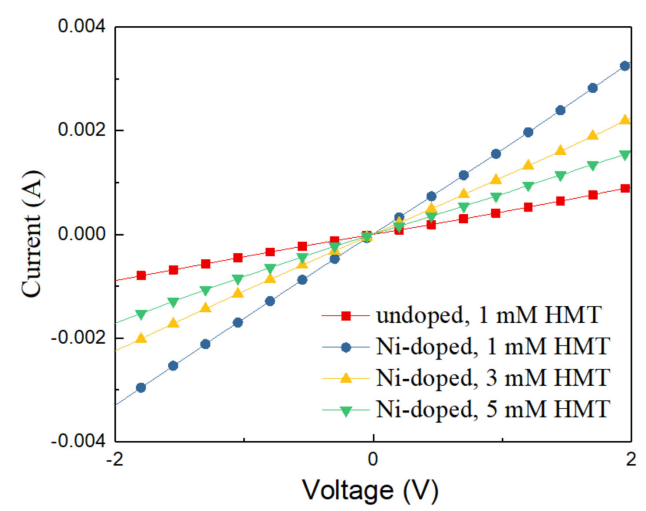

Figure 7. I-V characteristics of the electron-only devices based on the undoped and Ni-doped $\mathrm{ZnO}$ NWLs with HMT concentrations of 1,3 , and $5 \mathrm{mM}$. 


\subsection{Electrochemical Measurements}

To evaluate the electrochemical activity of the undoped and Ni-doped ZnO NWLs, $\mathrm{I}-\mathrm{V}$ characteristics of the four samples in a three-electrode cell were measured. In this part, we adopted LSV experiments to evaluate the activity of the catalyst for hydrogen and/or oxygen evolution reactions. Some bubbles were produced near the working electrode of the prepared $\mathrm{ZnO}$ NWLs when the bias voltage was applied. The LSV was measured to investigate the correlation between current densities and bias voltage, as shown in Figure 8. It can be seen that the undoped ZnO NWLs exhibited lower current density than the other three Ni-doped ZnO NWLs. The prepared Ni-doped ZnO NWLs exhibited better electrochemical activity, which could be attributed to Ni doping to enhance electron transport ability of ZnO. Particularly, the Ni-doped ZnO NWLs with the HMT concentration of $1 \mathrm{mM}$ revealed 6-fold higher current density at $1 \mathrm{~V}$ bias compared with the undoped $\mathrm{ZnO}$ NWLs, which demonstrates the best electrochemical performance due to the largest surface area and enhanced electron transport ability. It is reported that nanostructured catalyst has more active sites per geometric area to facilitate diffusions of ions, electrolytes, and generated gas [34]. Apart from our ZnO NWLs, graphdiyne NWLs have also been utilized as the catalyst for water splitting [35]. The structurecontrolled graphdiyne NWLs showed effective application in water oxidation, revealing a current density of $0.25 \mathrm{~mA} / \mathrm{cm}^{2}$ at a bias of $1 \mathrm{~V}$ and realizing significantly improved electrochemical activity and stability. Liu et al. utilized $\mathrm{ZnO}$ nanorods array as the catalyst for LSV measurement, receving a current density of $0.2 \mathrm{~mA} / \mathrm{cm}^{2}$ by applying a bias of $1 \mathrm{~V}$ [36]. Compared with those reports, the prepared Ni-doped ZnO NWs in this study possessed a much lower current response that should be further optimized. It is concluded that the design and synthesis of porous nanomaterials is a key issue to achieve efficient electrochemical performance with enlarged surface area and electrical conductivity.

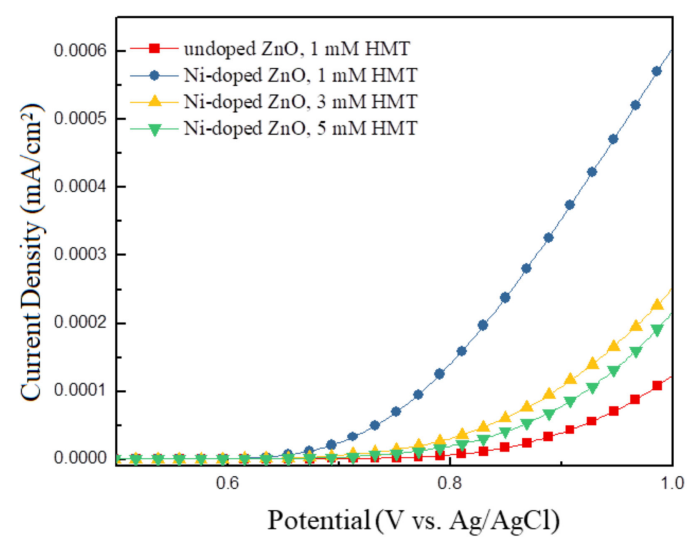

Figure 8. LSV curves for the undoped and Ni-doped ZnO NWLs with HTM concentrations of 1, 3, and $5 \mathrm{mM}$.

\section{Conclusions}

The $3 \mathrm{~mol} \%$ Ni-doped ZnO NWLs with sponge-like nanostructures on the ITO substrates were successfully prepared via the modified hydrothermal method through changing the HMT concentration from 1 to $5 \mathrm{mM}$. The incorporation of Ni atoms into ZnO NWLs lattices was verified by UV-Vis absorption and EDS experiments. The pores of Ni-doped $\mathrm{ZnO}$ NWLs are obviously smaller than those of the undoped one. Furthermore, Ni-doping helps to decrease surface roughness of $\mathrm{ZnO}$ NWLs. Besides, the pore size of ZnO NWLs can be adjusted by changing the HMT concentration, i.e., the pores become larger as the HMT concentration increases. However, the surface roughness of ZnO NWLs was enlarged when increasing the HMT concentration due to fast nucleation of $\mathrm{ZnO}$ crystallites. Through I-V measurement of electron-only devices, it can be found that Ni-doping and HMT incorporation show opposite effects on the electrical conductivity of devices. Owing to higher 
electron transport ability of the Ni-doped ZnO NWLs, an enhancement in electrochemical behavior has been demonstrated through water splitting.

Supplementary Materials: The following are available online at https:/ /www.mdpi.com/article/10 .3390/nano11081980/s1, Figure S1: Top-view SEM image of the Ni-doped ZnO NWLs with an HMT concentration of $7 \mathrm{mM}$, Figure S2: EDS result showing the element composition of Ni-doped ZnO NWLs using $1 \mathrm{mM} \mathrm{HMT.}$

Author Contributions: Conceptualization, S.-H.Y.; methodology, B.-C.J.; validation, B.-C.J. and S.-H.Y.; formal analysis, B.-C.J.; investigation, B.-C.J.; resources, S.-H.Y.; writing-original draft preparation, B.-C.J.; writing-review and editing, S.-H.Y.; supervision, S.-H.Y.; project administration, S.-H.Y. Both authors have read and agreed to the published version of the manuscript.

Funding: This research was financially supported by the Ministry of Science and Technology (MOST) of Republic of China (Grant No. MOST 108-2923-E-009-007-MY2) and the Higher Education Sprout Project of the Ministry of Education (MOE), Taiwan.

Conflicts of Interest: The authors declare no conflict of interest.

\section{References}

1. Bhati, V.S.; Hojamberdiev, M.; Kumar, M. Enhanced sensing performance of ZnO nanostructures-based gas sensors: A review. Energy Rep. 2020, 6, 46-62. [CrossRef]

2. Dahiya, A.S.; Sporea, R.A.; Poulin-Vittrant, G.; Alquier, D. Stability evaluation of ZnO nanosheet based source-gated transistors. Sci. Rep. 2019, 9, 2979. [CrossRef] [PubMed]

3. Röder, R.; Geburt, S.; Zapf, M.; Franke, D.; Lorke, M.; Frauenheim, T.; da Rosa, A.L.; Ronning, C. Transition metal and rare earth element doped zinc oxide nanowires for optoelectronics. Phys. Status Solidi B 2019, 256, 1800604. [CrossRef]

4. Godlewski, M.; Guziewicz, E.; Kopalko, K.; Łuka, G.; Łukasiewicz, M.I.; Krajewski, T.; Witkowski, B.S.; Gierałtowska, S. Zinc oxide for electronic, photovoltaic and optoelectronic applications. Low Temp. Phys. 2011, 37, 235-240. [CrossRef]

5. Tang, J.F.; Tseng, Z.L.; Chen, L.C.; Chu, S.Y. ZnO nanowalls grown at low-temperature for electron collection in high-efficiency perovskite solar cells. Sol. Energy Mater. Sol. Cells 2016, 154, 18-22. [CrossRef]

6. Zheng, G.; Wang, J.; Liu, H.; Murugadoss, V.; Zu, G.; Che, H.; Lai, C.; Li, H.; Ding, T.; Gao, Q.; et al. Tungsten oxide nanostructures and nanocomposites for photoelectrochemical water splitting. Nanoscale 2019, 11, 18968-18994. [CrossRef]

7. Özgür, Ü.; Alivov, Y.I.; Liu, C.; Teke, A.; Reshchikov, M.A.; Doğan, S.; Avrutin, V.; Cho, S.-J.; Morkoç, H. A comprehensive review of $\mathrm{ZnO}$ and materials devices. J. Appl. Phys. 2005, 98, 041301. [CrossRef]

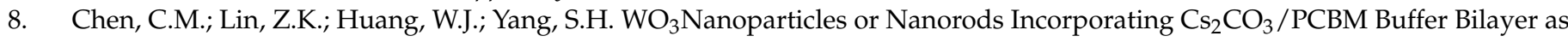
Carriers Transporting Materials for Perovskite Solar Cells. Nanoscale Res. Lett. 2016, 11, 464. [CrossRef]

9. Tsai, T.Y.; Yan, P.R.; Yang, S.H. Solution-Processed Hybrid Light-Emitting Devices Comprising $\mathrm{TiO}_{2} \mathrm{Nanorods}$ and $\mathrm{WO}_{3}$ Layers as Carrier-Transporting Layers. Nanoscale Res. Lett. 2016, 11, 516. [CrossRef]

10. Huang, Z.L.; Chen, C.M.; Lin, Z.K.; Yang, S.H. Efficiency enhancement of regular-type perovskite solar cells based on Al-doped $\mathrm{ZnO}$ nanorods as electron transporting layers. Superlattices Microstruct. 2017, 102, 94-102. [CrossRef]

11. Pellegrino, D.; Franzò, G.; Strano, V.; Mirabella, S.; Bruno, E. Improved synthesis of ZnO nanowalls effects of chemical bath deposition time and annealing temperature. Chemosensors 2019, 7, 18. [CrossRef]

12. Chen, P.Y.; Yang, S.H. Improved efficiency of perovskite solar cells based on Ni-doped ZnO nanorod arrays and Li salt-doped P3HT layer for charge collection. Opt. Mater. Express 2016, 6, 3651-3669. [CrossRef]

13. Feng, Z.; Rafique, S.; Cai, Y.; Han, L.; Huang, M.C.; Zhao, H. ZnO nanowall networks for sensor devices: From hydrothermal synthesis to device demonstration. ECS J. Solid State Sci. Technol. 2018, 7, Q3114-Q3119. [CrossRef]

14. Park, S.H.; Kim, S.H.; Han, S.W. Growth of homoepitaxial ZnO film on ZnO nanorods and light emitting diode applications. Nanotechnology 2007, 18, 055608. [CrossRef]

15. Lupan, O.; Chai, G.; Chow, L.; Emelchenko, G.A.; Heinrich, H.; Ursaki, V.V.; Gruzintsev, A.N.; Tiginyanu, I.M.; Redkin, A.N. Ultraviolet photoconductive sensor based on single ZnO nanowire. Phys. Status Solidi A 2010, 207, 1735-1740. [CrossRef]

16. Geng, W.; Kostcheev, S.; Sartel, C.; Sallet, V.; Molinari, M.; Simonetti, O.; Lérondel, G.; Giraudet, L.; Couteau, C. Ohmic contact on single ZnO nanowires grown by MOCVD. Phys. Status Solidi C 2013, 10, 1292-1296. [CrossRef]

17. Zhao, Y.; Li, C.; Chen, M.; Yu, X.; Chang, Y.; Chen, A.; Zhu, H.; Tang, Z. Growth of aligned ZnO nanowires via modified atmospheric pressure chemical vapor deposition. Phys. Lett. A 2016, 380, 3993-3997. [CrossRef]

18. Zhang, N.; Yi, R.; Shi, R.; Gao, G.; Chen, G.; Liu, X. Novel rose-like ZnO nanoflowers synthesized by chemical vapor deposition. Mater. Lett. 2009, 63, 496-499. [CrossRef]

19. Maeng, J.; Jo, G.; Choe, M.; Park, W.; Kwon, M.K.; Park, S.J.; Lee, T. Structural and photoluminescence characterization of ZnO nanowalls grown by metal organic chemical vapor deposition. Thin Solid Films 2009, 518, 865-869. [CrossRef]

20. Wojnarowicz, J.; Chudoba, T.; Lojkowski, W. A Review of Microwave Synthesis of Zinc Oxide Nanomaterials: Reactants, Process Parameters and Morphologies. Nanomaterials 2020, 10, 1086. [CrossRef] 
21. Mahmood, K.; Khalid, A.; Mehran, M.T. Nanostructured ZnO electron transporting materials for hysteresis-free perovskite solar cells. Sol. Energy 2018, 173, 496-503. [CrossRef]

22. Zheng, Y.Z.; Zhao, E.F.; Meng, F.L.; Lai, X.S.; Dong, X.M.; Wu, J.J.; Tao, X. Iodine-doped ZnO nanopillar arrays for perovskite solar cells with high efficiency up to 18.24\%. J. Mater. Chem. A 2017, 5, 12416-12425. [CrossRef]

23. Narayanan, G.N.; Ganesh, R.S.; Karthigeyan, A. Effect of annealing temperature on structural, optical and electricalproperties of hydrothermal assisted zinc oxide nanorods. Thin Solid Films 2016, 598, 39-45. [CrossRef]

24. Ji, Y. One-step method for growing of large scale ZnO nanowires on zinc foil. Mater. Lett. 2015, 138, 92-95. [CrossRef]

25. Tian, J.H.; Hu, J.; Li, S.S.; Zhang, F.; Liu, J.; Shi, J.; Li, X.; Tian, Z.Q.; Chen, Y. Improved seedless hydrothermal synthesis of dense and ultralong ZnO nanowires. Nanotechnology 2011, 22, 245601. [CrossRef] [PubMed]

26. Yan, D.; Cen, J.; Zhang, W.; Orlov, A.; Liu, M. Hydrothermal growth of ZnO nanowire arrays: Fine tuning by precursor supersaturation. CrystEngComm 2017, 19, 584-591. [CrossRef]

27. Tang, J.F.; Su, H.H.; Lu, Y.M.; Chu, S.Y. Controlled growth of ZnO nanoflowers on nanowall and nanorod networks via a hydrothermal method. CrystEngComm 2015, 17, 592-597. [CrossRef]

28. Liang, Z.; Gao, R.; Lan, J.L.; Wiranwetchayan, O.; Zhang, Q.; Li, C.; Cao, G. Growth of vertically aligned ZnO nanowalls for inverted polymer solar cells. Sol. Energy Mater. Sol. Cells 2013, 117, 34-40. [CrossRef]

29. Tang, J.F.; Chu, S.Y.; Lu, Y.M.; Tseng, Z.L. Using an Al reaction layer to control the morphology and optical properties of ZnO nanorods and nanowalls. Mater. Lett. 2016, 171, 195-199. [CrossRef]

30. Iwu, K.O.; Strano, V.; Mauro, A.D.; Impellizzeri, G.; Mirabella, S. Enhanced quality, growth kinetics, and photocatalysis of ZnO nanowalls prepared by chemical bath deposition. Cryst. Growth Des. 2015, 15, 4206-4212. [CrossRef]

31. Shin, K.S.; Park, H.J.; Kumar, B.; Kim, K.H.; Kim, S.H.; Kim, S.W. Inverted organic solar cells with ZnO nanowalls prepared using wet chemical etching in a KOH solution. J. Nanosci. Nanotechnol. 2012, 12, 1234-1237. [CrossRef] [PubMed]

32. Reddy, I.N.; Sreedhar, A.; Reddy, C.V.; Cho, M.; Kim, D.; Shim, J. Nickel-doped ZnO structures for efficient water splitting under visible light. Mater. Res. Express 2019, 6, 055517. [CrossRef]

33. Khan, H.R.; Akram, B.; Aamir, M.; Malik, M.A.; Tahir, A.A.; Choudhary, M.A.; Akhtar, J. Fabrication of Ni ${ }^{2+}$ incorporated ZnO photoanode for efficient overall water splitting. Appl. Surf. Sci. 2019, 490, 302-308. [CrossRef]

34. Li, X.; Hao, X.; Abudula, A.; Guana, G. Nanostructured catalysts for electrochemical water splitting: Current state and prospects. J. Mater. Chem. A 2016, 4, 11973-12000. [CrossRef]

35. Gao, X.; Li, J.; Du, R.; Zhou, J.; Huang, M.Y.; Liu, R.; Li, J.; Xie, Z.; Wu, L.Z.; Liu, Z.; et al. Direct synthesis of graphdiyne nan-owalls on arbitrary substrates and its application for photoelectrochemical water splitting cell. Adv. Mater. 2017, 29, 1605308. [CrossRef]

36. Liu, Y.; Yan, X.; Kang, Z.; Li, Y.; Shen, Y.; Sun, Y.; Wang, Li.; Zhang, Y. Synergistic Effect of Surface Plasmonic Particles and Surface Passivation Layer on ZnO Nanorod Array for Improved Photoelectrochemical Water Splitting. Sci. Rep. 2016, 6, 29907. [CrossRef] 